\title{
A Mouse Model of $\beta$-Thalassemia Shows a Liver-Specific Down-Regulation of Abcc6 Expression
}

\author{
Ludovic Martin, ${ }^{*}$ Vanessa Douet, ${ }^{\dagger}$ \\ Christopher M. VanWart, ${ }^{\dagger}$ Matthew B. Heller, $^{\dagger}$ \\ and Olivier Le Saux ${ }^{\dagger}$ \\ From the Department of Dermatology, ${ }^{*}$ University Hospital of \\ Angers, Angers, France; and the Department of Cell and \\ Molecular Biology, John A. Burns School of Medicine, University \\ of Hawaii, Honolulu, Hawaii
}

$\beta$-Thalassemia and pseudoxanthoma elasticum (PXE) are distinct genetic disorders. Yet, a dystrophic mineralization phenotype similar to PXE has frequently been associated with $\beta$-thalassemia or sickle cell anemia patients of Mediterranean descent. These calcifications are clinically and structurally identical to inherited PXE. As we previously excluded the presence of PXE-causing mutations in the $A B C C 6$ gene of $\beta$-thalassemia patients with PXE manifestations, we hypothesized that a molecular mechanism independent of gene mutations either altered the $A B C C 6$ gene expression or disrupted the biologic properties of its product in the liver or kidneys, which are the tissues with the highest levels of expression. To test this possibility, we investigated Abcc6 synthesis in the liver and kidneys of a $\beta$-thalassemia mouse model $\left(\boldsymbol{H} b b^{t h 3 /+}\right)$. We found a progressive liver-specific down-regulation of the $A b c c 6$ gene expression and protein levels by quantitative PCR, Western blotting, and immunofluorescence. The levels of Abcc6 protein decreased significantly at 6 months of age and stabilized at 10 months and older ages at $\sim 25 \%$ of the wild-type protein levels. We studied the transcriptional regulation of the Abcc6 gene in wild-type and $\boldsymbol{H b}^{\text {th3/+ }}$ mice, and we identified the erythroid transcription factor NF-E2 as the main cause of the transcriptional down-regulation using transcription factor arrays and chromatin immunoprecipitation. The $\boldsymbol{H b b}^{\text {th3/+}}$ mice did not develop spontaneous calcification as seen in the $\mathrm{Abcc6}^{-/-}$mice probably because the Abcc6 protein decrease occurred late in life and was probably insufficient to promote mineralization in the $\mathrm{Hbb}^{\text {th3/+ }}$ mouse $\mathrm{C57BL} / 6 \mathrm{~J}$ genetic background. Nevertheless, our result suggested that a similar decrease of $A B C C 6$ expression occurs in the liver of $\beta$-thalassemia patients and may be responsible for their frequent PXE-like manifestations. (Am J Pathol 2011, 178:774-783; DOI: 10.1016/j.ajpath.2010.10.004)

$\beta$-Thalassemia (MIM 141900) derives from mutations in the $\beta$-globin gene and results in the underproduction of $\beta$-globin chains. Excess $\alpha$-chains unbound to $\beta$-globin are unstable and precipitate in red blood cell precursors, forming inclusion bodies that are responsible for the intramedullary destruction of the erythroid precursors and the ineffective erythropoiesis that characterize $\beta$-thalassemia. Ineffective erythropoiesis in thalassemia major and certain intermedia patients results in considerable marrow expansion, causing bone deformities and iron overload that is further exacerbated by frequent blood transfusions. ${ }^{1} \beta$-Thalassemia is widespread throughout the Mediterranean, Africa, the Middle East, the Indian subcontinent, and Southeast Asia. In recent years, it has become apparent that a large number of Mediterranean patients affected by $\beta$-thalassemia or sickle cell anemia also develop manifestations similar to another inherited monogenic disorder called pseudoxanthoma elasticum (PXE). ${ }^{2}$

The PXE phenotype (MIM 264800) results from mutations in an ATP-binding cassette transporter called ABCC6. ${ }^{3-5}$ PXE is a rare autosomal recessive disease with an estimated prevalence of $1 / 25,000$ to $1 / 50,000$. It is characterized by skin, ocular, and vascular dystrophic calcifications affecting predominantly elastic fibers. ${ }^{6}$ The PXE phenotype progresses with age and displays high variability. The skin lesions are the prevailing characteristics that consist mostly of yellowish papules and/or plaques on flexor areas, such as the neck, axilla, and groin. ${ }^{6}$ The ocular lesions come from elastic fiber calcifi-

Supported by grants from the NIH (RR003061, to the Histology and Imaging Core Facility at the John A. Burns School of Medicine, University of Hawaii; and RR16453 and HL087289, to O.L.S.) and by Hawaii Community Foundation grants 20060395 and 20080443 (to O.L.S.).

Accepted for publication October 5, 2010.

Supplemental material for this article can be found on http://ajp. amjpathol.org and doi: 10.1015/j.ajpath.2010.10.004.

Address reprint requests to Olivier Le Saux, Ph.D., Department of Cell and Molecular Biology, John A. Burns School of Medicine, University of Hawaii, 651 Ilalo St., BSB 222, Honolulu, HI 96813. E-mail: lesaux@hawaii.edu. 
cation and ruptures of the Bruch's membrane, resulting in angioid streaks that later evolve toward choroidal neovascularization and retinal hemorrhages, causing loss of vision. ${ }^{7}$ The common vascular complications of PXE also appear to result from the dystrophic calcification of the internal elastic lamina of small-sized arteries. The broad spectrum of the vascular phenotype includes arteriosclerotic changes with intermittent claudication and more uncommonly early myocardial infarction and hypertension. ${ }^{8}$ The causality of the $A B C C 6$ gene was demonstrated in $2000{ }^{3-5}$ and since then the genetic characteristics of PXE have been well defined. ${ }^{9}$ However, the actual pathologic mechanism that links $A B C C 6$ to ectopic mineralization is unknown as the substrate or substrates transported by $A B C C 6$ has yet to be characterized. $A B C C 6$ is predominantly expressed in the liver and kidney and shows little or no expression in tissues affected by PXE. ${ }^{10-12}$ This suggests that PXE is a metabolic disorder with connective tissue manifestations and implies the presence of an abnormal circulating molecule or molecules that ultimately promotes calcification in peripheral tissues. We have detected the presence of unidentified circulating molecule(s) in the serum of adult PXE patients through their effects on elastic fibers deposited in cultures, ${ }^{13}$ and others have made similar observations. ${ }^{14,15}$

Although $\beta$-thalassemia and PXE are distinct genetic disorders, the frequent coexistence of both conditions is intriguing. Because PXE-like mineralization in $\beta$-thalassemia patients arise independently of $A B C C 6$ mutations $^{16}$ and is clinically and structurally identical to inherited PXE, ${ }^{17-20}$ the calcification of elastic fibers is very likely a phenocopy of inherited PXE. Therefore, we hypothesized that a converging molecular mechanism independent of genetic mutations alters the expression of $A B C C 6$ or disrupts the biologic properties of its product in the liver and/or kidneys as a secondary consequence of the hemoglobinopathy. To test this possibility, we investigated the level of Abcc6 synthesis in the liver and kidneys and the phenotype of a $\beta$-thalassemia mouse model $\left(H b b^{\text {th } 3 /+}\right)$ for a period of 14 months.

\section{Materials and Methods}

\section{Animals}

Wild-type C57BL/6J mice and the mouse model for $\beta$-thalassemia (designated here as $H b b^{\text {th } 3 /+}$ ) were purchased from Jackson laboratories (Bar Harbor, ME). Both $H b b-b 1$ and Hbb-b2 alleles are deleted in $H b b^{\text {th } 3 /+} .{ }^{21}$ As homozygous $\mathrm{Hbb}^{\text {th } 3 /+}$ mice die shortly after birth, animals were propagated and used in this study as heterozygous $\mathrm{Hbb}^{\text {th }} 3 / \mathrm{+}$. The phenotype of these mice is comparable to the human form of $\beta$-thalassemia intermedia. ${ }^{21}$ The genetic background of $\mathrm{Hbb}^{\text {th } 3 /+}$ mice is derived from a hybrid between the common C57BL/6J and 1290la strains. The animals were backcrossed at least eight times into C57BL/6J background before the beginning of this study. All mice were kept under routine laboratory conditions with 12 hours of a light-dark cycle with access ad libitum to water and standard chow. This study was approved by the Institutional Animal Care and Use Committee of the University of Hawaii.

\section{Plasma Membrane Isolation and Western Blot}

Plasma membranes from mouse liver and kidney were prepared following the method of Prpic and colleagues. ${ }^{22}$ Plasma membrane proteins were then separated by a standard $7 \%$ polyacrylamide gel electrophoresis. The presence of Abcc6 was revealed using immunoblots and an anti-Abcc6 polyclonal antibody. Immunolabeled proteins were visualized with the enhanced chemiluminescence system according to the manufacturer's instructions (ECL, Amersham Pharmacia, Piscataway, NJ).

\section{Antibodies}

The goat polyclonal anti-Abcc6 antibody sc-5787 and the rabbit polyclonal anti-Abcc6 antibody sc-25505 (Santa Cruz Biotechnology, Santa Cruz, CA) were used for detection of Abcc6, respectively, for immunochemistry and Western blotting. For chromatin immunoprecipitation studies, we used antibodies specific to p45-NF-E2 (C 19), Sp1 (PEP 2), MTF-1 (N 19), HNF1 $\alpha(\mathrm{H}-140)$, and HNF4 $\alpha(\mathrm{H}-171)$ (sc-291, sc-59, sc-26842, sc-10791, SC8987), respectively (Santa Cruz Biotechnology).

\section{Immunohistochemistry}

Six-micrometer sections were cut from frozen liver and kidney tissues. After 10 minutes of air-drying, sections were fixed with cold methanol for 30 minutes at $-20^{\circ} \mathrm{C}$ and washed in phosphate-buffered saline (PBS), pH 7.4. The sections were then blocked with a $5 \%$ solution of appropriate normal serum as a blocking reagent (SigmaAldrich, Saint Louis, MO) in PBS for 45 minutes at room temperature. The primary antibody was incubated overnight at $4^{\circ} \mathrm{C}$ (1:200 in PBS with $1 \%$ normal serum). The following morning, sections were washed several times with PBS with $0.01 \%$ Tween 20. Incubation with the secondary antibody was performed at room temperature for 45 minutes (1:200 in PBS with 1.5\% normal serum). After several washes with PBS with $0.01 \%$ Tween 20 and PBS, the sections were mounted with cover glasses using mounting medium containing propidium iodide (Vector Laboratories, Burlingame, CA). Slides were examined and images were collected using an Axioscope 2 fluorescent microscope (Zeiss, Thornwood, NY).

\section{Tissue Harvest}

Tissue from the liver and kidneys were excised and quickly rinsed in PBS, and they were snap-frozen in liquid nitrogen for TranSignal experiments and for RNA isolation. Tissues harvested for immunofluorescence were first immersed in Tissue-Tek OCT Compound (Electron Microscopy Sciences, Hatfield, PA), frozen on dry ice, and stored at $-80^{\circ} \mathrm{C}$. 


\section{Gene Expression Analysis}

Total RNA was isolated from tissue using the Qiagen RNeasy purification (Qiagen, Valencia, CA) procedure according to the manufacturer's instructions. Reverse transcription (RT) was performed on $1 \mu \mathrm{g}$ of total RNA with oligo $d(T)$ and the SuperScript III Reverse Transcriptase kit (Invitrogen, Carlsbad, CA). The cDNA level of the various murine genes examined in this study was determined using appropriate TaqMan probes and normalized to the expression of the Glyceraldehyde 3-phosphate dehydrogenase (Gapdh). All real-time PCR were performed with the ABI 7300 (Applied Biosystems, Foster City, CA), and each sample was analyzed in triplicate.

\section{Hydrodynamic Tail Vein Injections and Luciferase Assays}

To validate in vivo the activity of the Abcc6 promoter region used in this study, luciferase-conjugated (Firefly luciferase) reporter constructs were injected in 3-monthold C57BL/6J wild-type (WT) mice using the hydrodynamic tail vein injections procedure. We have previously described the Abcc6 promoter reporter constructs ${ }^{23}$ used in this study (pGL-162/+152 and pGL-2926/ $+152)$. The tail vein injections were performed with a 27-gauge needle with a volume of 1 to $2 \mathrm{ml}$ of DNA in a solution of PBS. Mice were injected with $50 \mu \mathrm{g}$ of a plasmid carrying a reporter construct and $25 \mu \mathrm{g}$ of a vector expressing the renilla luciferase under the control of the SV40 promoter (pRL-SV40), which was used as a positive reference. For negative controls, the pGL3-basic (Promega, Madison, WI) was used. The pRL-SV40 was also used as a control of DNA transfer efficiency in the liver, kidneys, and spleen. These tissues were collected from each injected mouse 7 hours postinjection for the luciferase assay. Tissues were homogenized in the following buffer (250 mmol/L sucrose, $5 \mathrm{mmol} / \mathrm{L}$ HEPES, $\mathrm{pH}$ 7.4, $1 \mathrm{mmol} / \mathrm{L}$ EDTA) (Complete Protease Inhibitor Cocktail, Roche, Mannheim, Germany), centrifuged, and the pellets were resuspended in a lysis buffer $(20 \mathrm{mmol} / \mathrm{L}$ HEPES, $\mathrm{pH} 7.4,25 \%$ glycerol, $0.42 \mathrm{M} \mathrm{NaCl}, 1.5 \mathrm{mmol} / \mathrm{L}$ $\mathrm{MgCl}_{2}, 0.2 \mathrm{mmol} / \mathrm{L}$ EDTA, $0.5 \mathrm{mmol} / \mathrm{L}$ dithiothreitol) containing protease inhibitors. Both firefly and renilla luciferase activities were measured using Turner Designs Luminometer Model TD-20/20 Genetic Reporter System (Promega, Sunnyvale, CA). The transfection efficiency was normalized to the renilla luciferase activity and the quantity of total proteins in tissue extracts. The relative luciferase activity was defined as the ratio of firefly/renilla/mg of tissue extract protein. Each assay was performed in triplicate.

\section{Protein/DNA Array}

The $-2926 /+152$ bp promoter fragment was amplified using the primers 5'-GGGGTACCTGACTCACATATTTCACGCC-3' and 5'-GGGGTACCGTTTGTCTTACAGCTTCCCG-3'. The PCR product was verified by direct sequencing. This PCR fragment corresponding to the mouse Abcc6 promoter region was digested with
Kpnl and subsequently labeled with biotin using Bio-16dUTP (Roche) and a terminal transferase (New England Biolabs, Beverly, MA). The labeled product was isolated with streptavidin magnetic beads according to the manufacturer's instructions (Roche). The promoter fragments coupled to magnetic beads were then incubated with 500 $\mu \mathrm{g}$ of nuclear extracts from the liver for 2 hours at $4^{\circ} \mathrm{C}$ in the presence of an excess of dC-dl to prevent nonspecific binding (Amersham Pharmacia). Nuclear extracts were prepared from the liver using a nuclear extraction kit (Panomics, Fremont, CA). After several washes, the bound proteins were dissociated from the promoter DNA fragments using an elution buffer $[20 \mathrm{mmol} / \mathrm{L}$ Tris- $\mathrm{HCl}, \mathrm{pH}$ $8,1 \mathrm{mmol} / \mathrm{L}$ EDTA, $10 \%$ glycerol, $1 \mathrm{mmol} / \mathrm{L}$ 0.01\% (v/v) dithiothreitol, Triton $\mathrm{X}-100,2 \mathrm{M} \mathrm{NaCl}$. The transcription factors (TFs) pulled down with this method were identified by Transignal Protein/DNA array (Panomics). Hybridization signals were visualized by chemiluminescence and X-ray film. Array hybridization was performed in duplicate.

\section{Chromatin Immunoprecipitation Assays}

Chromatin immunoprecipitation assays were performed according to standard protocol with some modifications. ${ }^{24}$ Tissues were fixed with $1 \%$ formaldehyde for 15 minutes at room temperature and the cross-linking was then stopped with a solution of $125 \mathrm{mmol} / \mathrm{L}$ of glycine. Tissues were homogenized, the cells were lyzed, and the pull-down nuclei were resuspended in nuclear lysis buffer. Cross-linked chromatin was sheared by sonication to an average size of about $500 \mathrm{bp}$, which was visualized by electrophoresis on a $1 \%$ agarose gel. The soluble fraction of the chromatin fragments was then pre-cleared with protein A/G agarose beads (Santa Cruz Biotechnology), which was previously blocked with sonicated salmon sperm. Aliquots from the supernatant (50 $\mu \mathrm{g}$ DNA) were incubated with $2 \mu \mathrm{g}$ of the appropriate antibodies (Santa Cruz Biotechnology) overnight at $4^{\circ} \mathrm{C}$. Immuno-complexes containing the chromatin fragment were recovered by centrifugation and washed with a succession of lithium chloride and Tris-EDTA buffers. As a negative control, an aliquot of the cross-linked chromatin was immunoprecipitated with nonimmunized control serum instead of a specific antibody (designated as the NoAb fraction). An aliquot of the supernatant obtained after pre-clearing with protein $A / G$ agarose was used as positive control (designated as the Input fraction). The immunoselected chromatin was eluted from the protein $\mathrm{A} / \mathrm{G}$ agarose and incubated at $65^{\circ} \mathrm{C}$ overnight to reverse formaldehyde cross-links. The resulting immunoprecipitated DNA was purified with a PCR product purification kit (Qiagen) and was analyzed for specific enrichment by quantitative PCR analysis. The quantification of the coimmunoprecipitated promoter fragment was based on Chakrabarti and colleagues. ${ }^{24}$ The relative proportions of co-immunoprecipitated Abcc6 promoter were determined based on the threshold cycle value for each PCR reaction. For each TF analyzed, samples were quantified in triplicate from three independent immunoprecipitations. A melting curve analysis was performed for each 
sample after PCR amplification to ensure that a single product was obtained. The primers used to amplify the proximal promoter region of $A b c c 6$ have been previously described. ${ }^{23}$ For these experiments, a 7300 RealTime PCR system (Applied Biosystems) was used. Each reaction was performed in triplicate with the following conditions: $50^{\circ} \mathrm{C}$ for 2 minutes; $95^{\circ} \mathrm{C}$ for 10 minutes; and 40 cycles of $95^{\circ} \mathrm{C}$ for 15 seconds, and $60^{\circ} \mathrm{C}$ for 1 minute.

\section{Statistical Analysis}

Data were analyzed with the statistical software PRISM (GraphPad Software Inc, La Jolla, CA). Statistical analyses were performed by using the two-tailed unpaired Student's $t$-test to determine statistical difference between the 2 groups. Results were expressed as mean \pm SEM and considered significant for $P<0.05$.

\section{Results}

\section{Abcc6 mRNA Levels in $\mathrm{Hbb}^{\text {th } 3 /+}$ Mice}

To determine whether the altered physiology of $\mathrm{Hbb}^{\text {th3/+ }}$ mice had an influence on Abcc6 expression, we first determined the levels of $A b c c 6$ mRNA in the tissues with the most $A b c c 6$ expression (ie, the liver and kidneys) for a period of 14 months. This analysis was carried out using real-time quantitative PCR. Figure 1 summarizes the results obtained. In WT liver, Abcc6 expression was readily detectable at birth and increased rapidly during the first month to reach a plateau followed by a modest increase at 14 months (Figure 1A). In WT kidneys, the expression followed a similar trend and reached a gently sloping plateau at 6 months (Figure 1B). In the liver of $H b b^{\text {th } 3 /+}$ mice, the profile of Abcc6 mRNA levels was different (Figure 1A). Up to 6 months, the Abcc6 expression was somewhat lower than in WT mice, but the difference was not statistically significant $(P>0.5)$. However, beginning at 6 months, the Abcc6 expression decreased significantly to an average of $82 \%$ of the WT levels. At 10 months, Abcc6 expression had dropped to $55 \%$ of the wild-type levels and at 14 months, the mRNA expression had further decreased to $44 \%$. Despite levels much lower than in the liver, ${ }^{12}$ the kidney expression profile in $H b b^{\text {th } 3 /+}$ mice presented no major difference when compared to WT mice (Figure 1B) $(P>0.2)$. We also evaluated the level of $A b c c 6$ expression in the small intestine at 10 months and found no change between WT and $H b b^{\text {th } 3 /+}$ mice (Figure $1 C$ ).

Our results showed that the Abcc6 gene expression in $H b b^{\text {th } 3 /+}$ mice is down-regulated specifically in the liver. To determine whether these tissue-specific changes in expression were unique to $A b c c 6$, we examined the levels of expression of selected ATP-binding cassette transporters of the same subfamily $(A b c c 1, A b c c 2, A b c c 3$, $A b c c 5)$ in the liver of 10-month-old mice with the same quantitative method (Figure 2). The hepatic expression of Abcc1 and Abcc5 were very low, but quantifiable, with similar levels observed in both WT and $H \mathrm{bb}^{\text {th } 3 /+}$ mice. Of the 5 Abcc genes tested, the expressions of $A b c c 2$ and Abcc3 were proportionally the highest measured. Al-
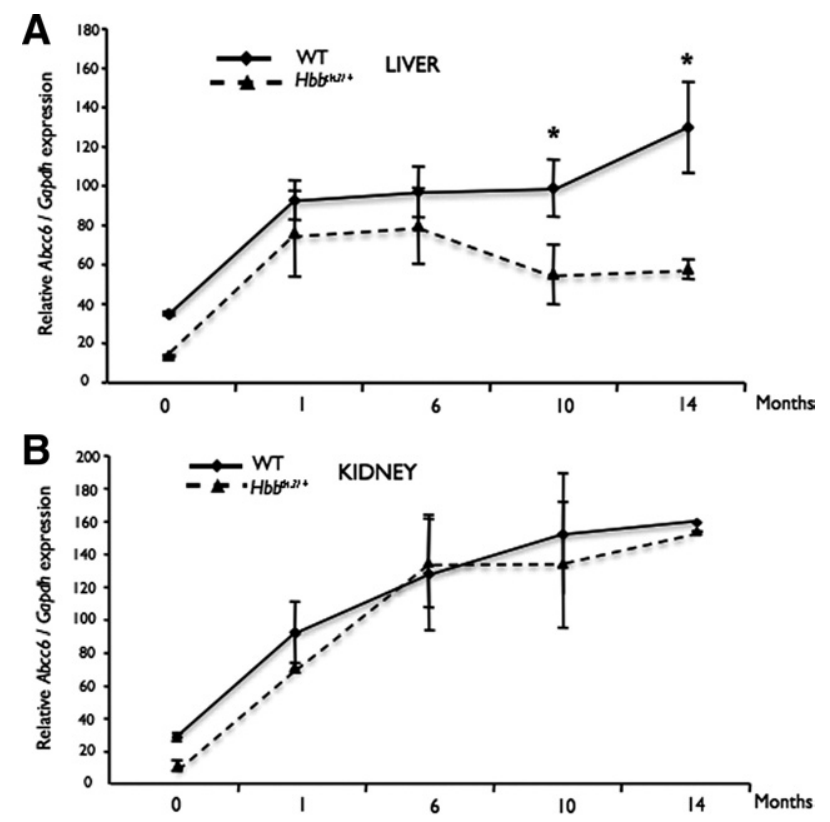

C

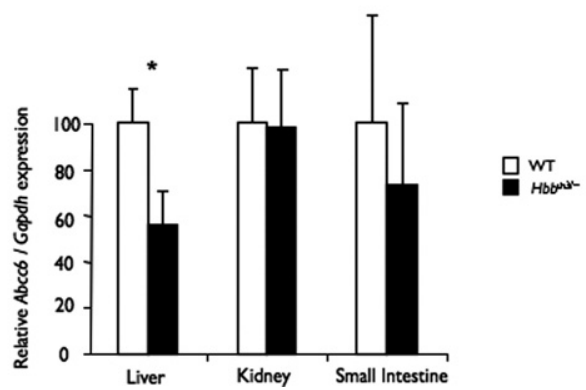

Figure 1. $A b c c 6$ gene expression in the liver, kidneys, and small intestine of wild-type (WT) and $\beta$-thalassemia mouse model $\left(H b b^{\text {th } 3 /+}\right)$ mice. Total RNA was isolated from mouse liver (A), kidney $(\mathbf{B})$, and intestines $(\mathbf{C})$ of WT and $\mathrm{Hbb}^{t h 3 /+}$ mice from birth to 14 months of age and was reverse transcribed. Quantitative PCRs were performed using TaqMan probes (Applied Biosystems, Foster City, CA) specific to mouse Abcc6 and Gapdb cDNA. Unit represents the relative expression of the $A b c c 6$ normalized to the housekeeping gene in the liver (A) and in the kidneys (B). In C, Abcc 6 mRNA levels in the liver, kidneys, and small intestine were determined at 10 months of age and normalized to WT levels. Standard errors are indicated. ${ }^{*} P<0.05$.

though the expression levels of $A b c c 3$ were unchanged, those of $A b c c 2$ showed a decrease of $30 \%(P<0.05)$.

\section{Abcc6 Protein Levels in $\mathrm{Hbb}^{\text {th } 3 /+}$ Mouse}

The levels of Abcc6 protein in the plasma membrane of the liver and kidneys were also evaluated by Western blotting to determine whether they followed the same decrease as the Abcc6 mRNA (Figure 3). Because Abcc6 is located on the basolateral membrane of hepatocytes and kidney cells, WT and $H b b^{\text {th } 3 /+}$ tissue extracts were subjected to ultracentrifugation to isolate the plasma membrane. The signal intensity obtained after immunoblotting was quantified with a Kodak Gel Logic 200 imager system (Carestream Health Inc, Woodbridge, CT). In the fractions isolated from WT liver, Abcc6 proteins were detectable at 1 month of age and the protein levels increased significantly with time (not shown). Similar results were obtained with fractions isolated from WT kid- 


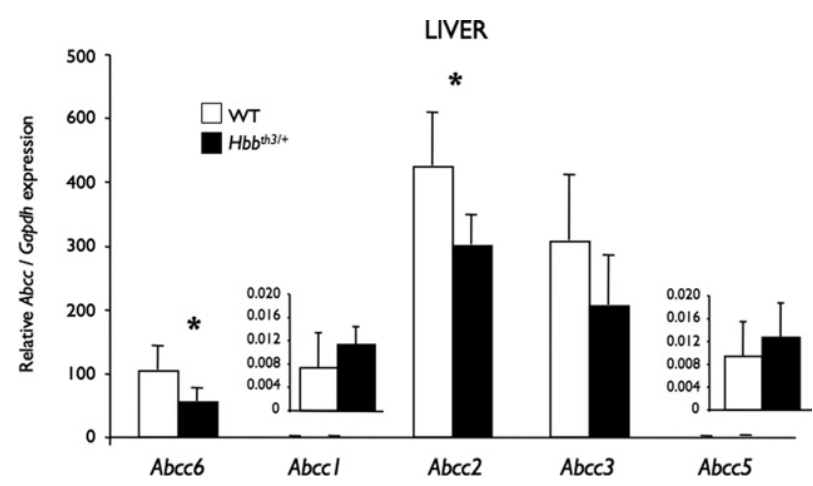

Figure 2. Comparison of expression levels of $A b c c 1, A b c c 2, A b c c 3, A b c c 5$, and $A b c c 6$ in the liver of 10 -month-old wild-type (WT) and $\beta$-thalassemia mouse model $\left(H b b^{\text {th } 3 /+}\right)$ mice. Total RNA was prepared from mouse liver of WT and $\mathrm{Hbb}^{\text {th } 3 /+}$ mice (as described in the Materials and Methods section) and reversed transcribed. Quantitative PCRs were performed using TaqMan probes (Applied Biosystems, Foster City, CA) specific to mouse Abcc1, Abcc2, Abcc3, $A b c c 5, A b c c 6$, and $G a p d b$ cDNA. Units represent mRNA levels relative to the WT Abcc6 expression level. Standard errors are shown. ${ }^{*} P<0.05$.

ney, although a 10-fold increase in total protein load (100 $\mu \mathrm{g})$ compared to the liver was necessary to achieve a reliable detection. During the age span examined, we found that in $\mathrm{Hbb}^{\text {th } 3 /+}$ mice, the Abcc6 protein levels in liver decreased significantly between 1 and 6 months of age, reaching $57 \%$ of the WT levels at 6 months and $24 \%$ at 10 and 14 months (Figure 3A) $(P<0.05)$. Similar to the kidney gene expression, we found that the renal fractions isolated from $\mathrm{Hbb}^{\text {th } 3 /+}$ mice showed no major difference at each time point when compared to WT levels (Figure 3B).

Because the membrane localization of Abcc6 at the basolateral side is important for its nominal function, we also verified whether the cellular localization of Abcc6 in $\mathrm{Hb} b^{\text {th } 3 /+}$ mice was also altered. We performed immunohistochemistry with frozen sections of the liver and kidney of both knockout and WT mice. The results are illustrated in Figure 4. The plasma membrane localization of Abcc6 in normal mouse liver was evident at all ages, with a somewhat higher intensity in adult mice. However, the immunostaining patterns of Abcc6 in liver sections of
$\mathrm{Hb}^{\text {th } 3 /+}$ mice were dramatically changed (Figure 4A). Indeed, the liver sections of $H b b^{\text {th } 3 /+}$ mice revealed a weaker signal for Abcc6 at 6 months. At older ages, the immunostaining signals were clearly diminished when compared to WT liver and were limited to small sections of the plasma membrane. Although localized onto the basolateral membrane, Abcc6 did not present a uniform localization around the plasma membrane, but rather a spotty and interrupted distribution, which was consistent with the lower amount of Abcc6 in liver determined by Western blotting. Similar to the previous results, the kidney sections displayed apparently normal intensity and a typically diffused signal ${ }^{11}$ for Abcc6 in $\mathrm{Hb}^{\text {th }} \mathrm{Al+}$ mice (Figure 4B).

\section{Transcription Factors}

\section{Similarities between Abcc2 and Abcc6 Promoters}

Although the down-regulation of Abcc2 expression in liver was modest compared to that of Abcc6, it was statistically significant. This suggested that promoters of these genes both responded to similar stimuli from the thalassemia physiology, perhaps via comparable regulatory signals. The regulatory sequences of the mouse and human $A b c c 2 / A B C C 2$ and $A b c c 6 / A B C C 6$ have been previously studied, ${ }^{25,26}$ and the published sequences allowed an in silico comparative analysis (not shown). We have previously shown that Sp1, HNF4 $\alpha$, and NF-E2 are key transcriptional regulators of the mouse Abcc6 expression, whereas others have demonstrated the transactivation potential of $\mathrm{NF}-\kappa B^{27,28}$ for the human ABCC6 gene. We found an overall similarity in TF-binding sites and their respective distribution, upstream of the initiator codon in both Abcc6 and Abcc2 genes. The presence of multiple NF-E2 binding sites in the distal region of both promoters is particularly interesting because this TF plays a major role in the transactivation of $A b c c 6,{ }^{23}$ and this also suggests that it may play a role on the transcriptional regulation of $A b c c 2$. Similarly, the binding sites for $\mathrm{Sp} 1, \mathrm{HNF} 4 \alpha, \mathrm{NF}-\kappa \mathrm{B}$, and MTF-1 are present on both regulatory sequences in similar
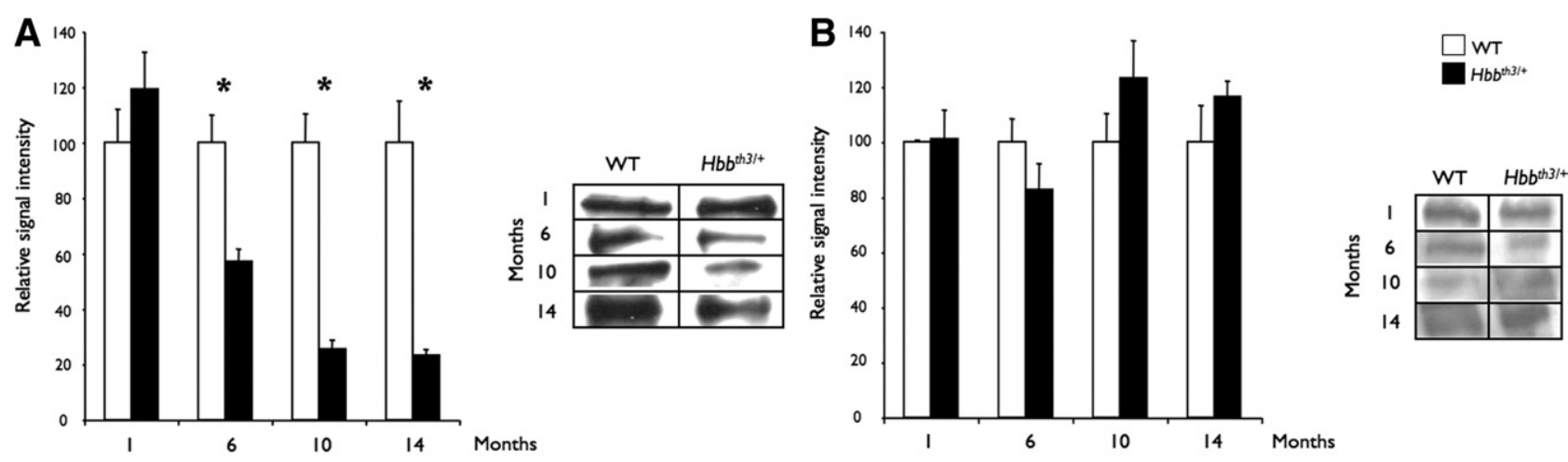

Figure 3. Western blot quantification of Abcc6 protein levels in the liver and kidneys of wild-type (WT) and $\beta$-thalassemia mouse model $\left(H b b^{\text {th } 3 /+}\right.$ ) mice. The plasma membranes from WT and $\mathrm{Hbb}^{\text {th } 3 /+}$ mouse liver $(\mathbf{A})$ and kidney (B) were isolated at 1, 6, 10, and 14 months. Proteins were separated onto a $7 \%$ polyacrylamide gel, transferred into nitrocellulose membrane, and probed with an antibody raised against Abcc6 (Santa Cruz Biotechnology, Santa Cruz, CA). The Western blot signal intensities were quantified with a Kodak Gel Logic 200/Kodak 1D and associated software (Carestream Health Inc, Woodbridge, CT). Representative images are included. The results are shown with standard errors and relative to WT levels at each age. ${ }^{*} P<0.05$. 


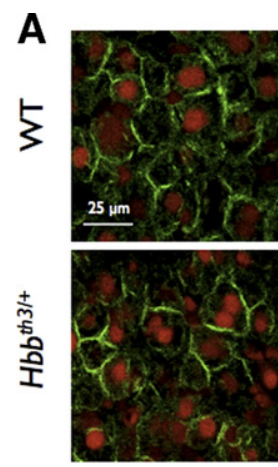

I
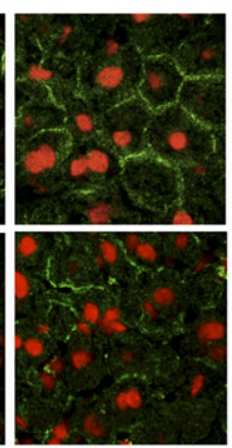

6
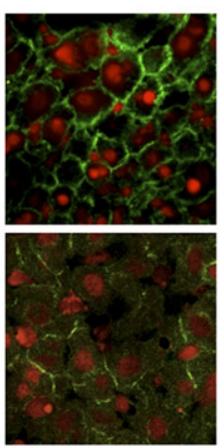

10

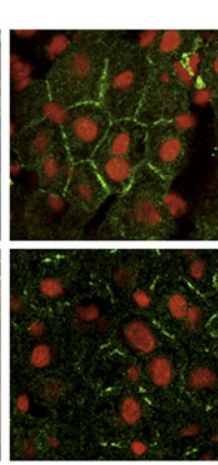

B

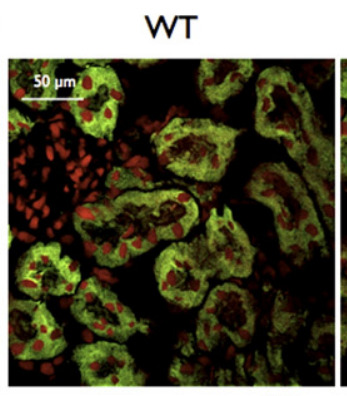

10 months

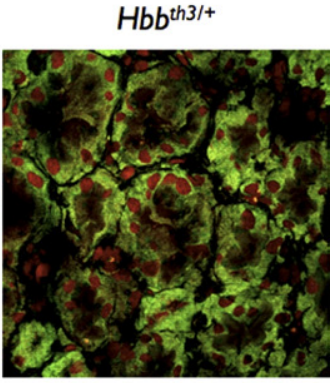

14 Months

Figure 4. Immunofluorescent detection of Abcc6 in the liver and kidney of wild-type (WT) and $\beta$-thalassemia mouse model $\left(H b b^{\text {th } 3 /+}\right.$ ) mice. The immunofluorescent labeling of Abcc6 in the liver $(\mathbf{A})$ and kidney $(\mathbf{B})$ of WT and $H b b^{t h 3 /+}$ mice was performed on frozen sections. Representative images are shown. A polyclonal antibody raised against Abcc6 (Santa Cruz Biotechnology, Santa Cruz, CA) was used in combination with an Alexafluor 488 secondary antibody. The nuclei of hepatocyte were counterstained with propidium iodide. Imaging was performed with a fluorescent microscope and the images were processed with Photoshop CS3 (Adobe, Adobe Systems, Inc, San Jose, CA). A: Comparison of immunofluorescent signals for Abcc6 in the liver of WT (upper panels) and $\mathrm{Hbb}^{t h 3 /+}$ mice (lower panels). No obvious difference was visible at 1 month of age, whereas the membrane signals at 6, 10, and 14 months were clearly reduced and presented a punctuated appearance. The animal ages are indicated below the images and scale bars [25 $\mu \mathrm{m}$ for the liver (A) and $50 \mu \mathrm{m}$ for the kidney (B)] are shown.

order, which suggested that $A b c c 2$ and $A b c c 6$ might share some regulatory signals.

\section{TF Profiling of Abcc6 Promoter in Normal and $\mathrm{Hbb}^{\text {th } 3 /+}$ Mice}

In the liver of $H b b^{\text {th } 3 /+}$ mice, we found an age-dependent decrease of Abcc 6 mRNA and protein levels. Because the changes in Abcc6 levels could result from modifications of transcriptional regulation, we investigated potential alterations in TF binding patterns on the Abcc6 promoter in the liver of $H b b^{\text {th } 3 /+}$ mice. To initiate the functional analysis of the Abcc6 promoter, we first confirmed that the promoter construct we previously described $^{23}$ was fully functional in vivo in the liver of WT mice. We compared these results with a minimally regulated construct carrying only the promoter proximal region. The full-length construct encompassed nearly all $(\sim 2.9 \mathrm{~kb})$ of the intervening sequence between Abcc6 and a gene positioned upstream in a divergent arrangement (Nomo1) plus $162 \mathrm{bp}$ downstream of the start codon. The shorter construct extended 152 bp upstream and $162 \mathrm{bp}$ downstream of the initiator codon. As we planned to use tissue extracts to perform our study, we tested the promoter activity of both constructs in the liver of WT mice. We injected the reporter constructs in the animals by hydrodynamic tail vein injection ${ }^{29}$ that achieves a high level of gene delivery in the liver and other tissues. The results obtained showed that both promoters were indeed functional in vivo and displayed a higher activity in the liver than in the kidneys or spleen (Figure 5). The proximal promoter construct $(p-152 /$ +162 ) yielded the highest luciferase expression in the liver (16-fold) when compared to the negative controls, whereas the full-length $(p-2926 /+162)$ construct led to a little lower level (9.5-fold) of luciferase expression (Figure $5)$. A significant promoter activity of the proximal fragment (-152/+162 bp) was detected in kidneys (2.3-fold) and in spleen (fourfold) despite a lower transfection effi- ciency of these tissues, as determined by the use of the pRL-SV40 control vector (data not shown). This is explained by the lack of most of the regulatory elements found upstream. In contrast, the full-length construct $(-2926 /+162$ bp) produced little luciferase activity in the kidneys or spleen.

Then we determined if the profiles of the liver TF binding to the $-2926 /+162$ bp Abcc6 promoter sequence were similar in WT and $\mathrm{Hb}^{\text {th } 3 /+}$ mice. For this experiment, we used the TranSignal technology (Panomics). Nuclear proteins were extracted from 10-month-old WT and $H b b^{t h 3 /+}$ mouse livers. We used the $-2926 /+162 b p$ fragment to isolate TFs binding to this promoter region. The profile of these TFs was determined using the TranSignal protein/DNA arrays I and III containing 54 and 94 transcription factors, respectively (Supplemental Figure

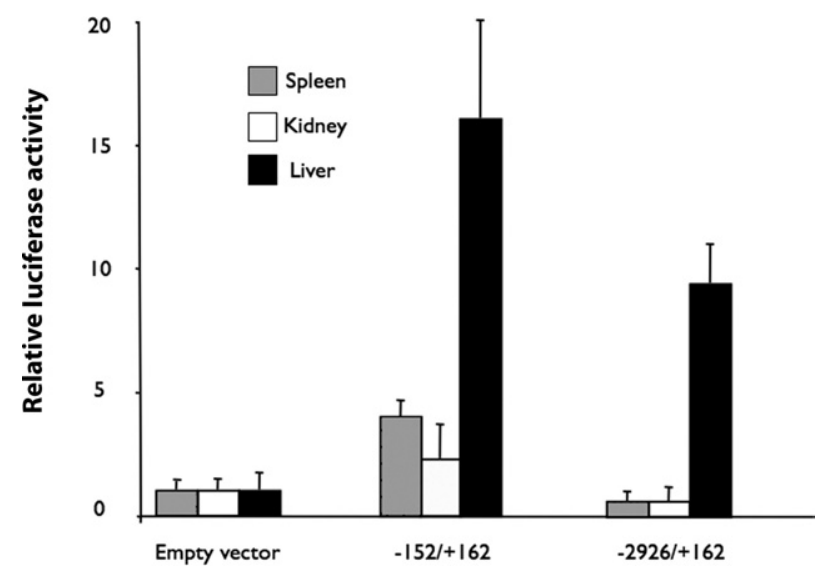

Figure 5. The mouse $A b c c 6$ promoter constructs are functional in vivo. The promoter construct $(50 \mu \mathrm{g}), \mathrm{p}-152 /+162 \mathrm{bp}$, and $\mathrm{p}-2926 /+162 \mathrm{bp}$ were linked to a luciferase reporter gene and the positive control $(25 \mu \mathrm{g})$ and pRL-SV40 were co-injected by hydrodynamic tail vein injection with phosphate-buffered saline (volume, $1 \mathrm{ml}$ ) in wild-type (WT) mice. For negative controls, WT mice were co-transfected with the pGL-3basic vector. The relative luciferase activity was normalized to the renilla luciferase activity. The data are shown relative to the promoterless pGL-3 basic vector with standard errors $(n=3)$. 
S1A, see http://ajp.amjpathol.org). Because the -2926/ +162 bp fragment encompassed the entire diverging region between Abcc6 and Nomo1, we expected the TF profile to include those specific to both genes.

Supplemental Figure S1B (see http://ajp.amjpathol.org) summarizes the 24 TFs with the highest signals identified in the pull-down extracts from WT liver extracts. The -2926/+162 bp promoter region displayed a consensus-binding sequence for half of the identified TFs. Interestingly, the consensus sequence for Stat4, TR, RAR, GRE, E2F1, and PYR was not found on the Abcc6 promoter, whereas these TFs displayed strong hybridization signals (Supplemental Figure S1A, see http:// ajp.amjpathol.org). The experiment was replicated with TFs extracted from the liver of $H b b^{\text {th } 3 /+}$ mice and pulled down with the same $-2926 /+162$ bp promoter region. The comparison of TF patterns between WT and $H \mathrm{bb}^{\text {th } 3 /+}$ mice revealed that the same transcription factors were identifiable, but most displayed lowered signal intensities, which was reproducible with a second set of array assays (Supplemental Figure S1A, see http://ajp. amjpathol.org). Ten TFs with large reductions in signal intensity were identified (E2F1, GRE, HNF4, NF-E2, Stat-4, TR, USF-1, CEA, CREB2, WT1) while a single one (MTF-1) had a slight increase. This was particularly interesting becuse we previously showed that two of the down-regulated TFs (HNF4 $\alpha$ and NF-E2) are important transcriptional activators of the mouse Abcc6 expression. ${ }^{23}$ Note that NF-E2 is in fact a heterodimer composed of two subunits of $45 \mathrm{kDa}$ and $18 \mathrm{kDa}$. The gene coding the $18-k D a$ subunit is widely expressed, whereas that of the $45-k D a$ subunit is restricted to erythroid precursors and the liver. ${ }^{23,30}$

These results suggested that the down-regulation of the $A b c c 6$ gene in $H b b^{\text {th } 3 /+}$ mice might be mediated by an altered binding of transcriptional activators on the Abcc6 promoter. To confirm these results, using a combination of chromatin immunoprecipitation assay and quantitative $\mathrm{PCR},{ }^{23}$ we quantified the specific association of NF-E2 and HNF $4 \alpha$ (as well as Sp1 and HNF1 $\alpha$ for control purposes) to the $A b c c 6$ promoter in liver samples from WT and $H b b^{\text {th } 3 /+}$ mice. We also chose to examine MTF-1, as it was the only TF showing an apparent increase in binding. In WT liver extracts, we found that the relative amount of DNA pulled down with antibodies to NF-E2, Sp1, and $\mathrm{HNF} 4 \alpha$ were 1.5 - to 2.5 -fold greater than those in negative controls, indicating an association of these TFs with the Abcc6 proximal promoter (Figure 6). As expected, ${ }^{12,23}$ pull-down results obtained with $\mathrm{HNF} 1 \alpha$ and MTF-1 showed no major association. When chromatin immunoprecipitation assay was carried out with $\mathrm{Hbb}^{\text {th } 3 /+}$ liver extracts, we found similar results for $\mathrm{HNF} 1 \alpha$, Sp1, and HNF $4 \alpha$ when compared to WT levels (Figure 6). However, the relative association levels of NF-E2 with the Abcc6 promoter were dramatically decreased in $H \mathrm{bb} \mathrm{b}^{\text {th } 3 /+}$ liver extracts, whereas that of MTF-1 showed a slight increase, all consistent with the array data.

The levels of gene expression for p45-NF-E2 subunit and MTF-1 were found to be similar in WT and $\mathrm{Hbb}^{\text {th } 3 /+}$ mouse livers (data not shown).

\section{Ectopic Mineralization Phenotype of $\mathrm{Hbb}^{\text {th3/+ }}$ Mice}

Calcification of elastic fibers in the tissues that typically affect $A b c c 6^{-1-}$ mice ${ }^{31,32}$ was explored using von Kossa and Alizarin red S staining. No obvious positive signs of mineralization were found in the whiskers, vascular tissues, eyes, kidneys, liver, and skin of $H b b^{\text {th } 3 /+}$ mice from birth to 14 months of age (data not shown).

\section{Discussion}

Typical PXE manifestations have been described in Mediterranean subjects with $\beta$-thalassemia and sickle cell anemia with an unusually large prevalence. ${ }^{2}$ Because this high prevalence (as much as $85 \%$ ) for one or more of the typical PXE lesions suggested a possible co-inheritance of both conditions; we searched for causative mutations in the $A B C C 6$ gene in a small subset of patients with clearly diagnosed $\beta$-thalassemia major and wellcharacterized PXE symptoms, but no PXE mutation could be detected. Therefore, we concluded that the development of ectopic calcifications in the connective tissues of $\beta$-thalassemia patients represented an acquired rather than inherited condition. ${ }^{16}$ Others have previously reached similar conclusions based on clinical observations, but none of these studies have established an association between the most evident characteristics of $\beta$-thalassemia (hemoglobin, serum ferritin levels, or even chelation therapies) and elastic fiber calcification. ${ }^{2,33-39}$ More recently, iron overload of tissues and associated oxidative stress found in hemolytic disorders was proposed as a potential effector of elastic fiber damage, notably in $\beta$-thalassemia. Indeed, excess of iron impairs
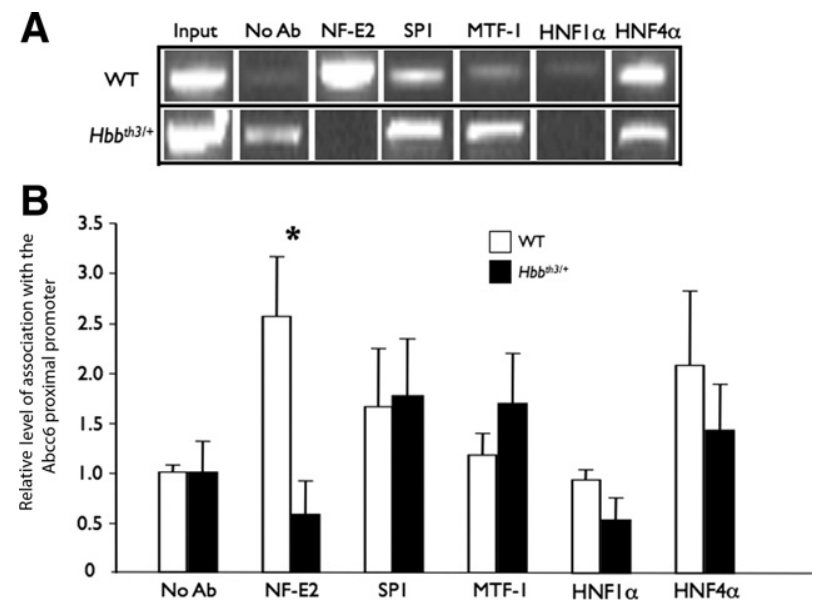

Figure 6. The transcription factors NFE2 and MTF-1 may be involved in the differential expression of $A b c c 6$ in the liver of $\beta$-thalassemia mouse model $\left(H b b^{\text {th } 3 /+}\right)$ mice. Soluble chromatin prepared from the liver of wild-type (W'T) (A, upper panels) and $H b b^{t h 3 /+}$ mice (A, lower panels) was immunoprecipitated with an antibody raised against the indicated transcription factor. Negative control immunoprecipitations were performed with a nonimmunized control serum (NoAb). Chromatin preparations were analyzed for specific enrichment by PCR (A) and measured by quantitative PCR (B) using a pair of primers covering the promoter region of interest. For a positive control, chromatin extracts before immunoprecipitation (Input) was amplified in parallel. Standard errors are shown. ${ }^{*} P<0.05$. 
elastic fibers both at the transcriptional and protein synthesis levels. ${ }^{40}$ Even if the effect of iron on elastic fibers might contribute to the elastopathy of $\beta$-thalassemia, it can hardly explain the complete clinical and structural similarities of the symptoms with inherited PXE. In fact, in hereditary hemochromatosis, whether in human patients or a mouse model, no ectopic calcification of the connective tissue has been reported. Therefore, we hypothesized that the pathomechanism for elastic fiber mineralization in $\beta$-thalassemia resulted from decreased $A B C C 6$ expression and/or altered protein function.

For this reason, we examined the production of Abcc6 (gene expression and protein synthesis) in a mouse model of $\beta$-thalassemia $\left(\mathrm{Hbb}^{\text {th }}{ }^{++}\right)$during a 14 -month period of time. Although human and mouse ABCC6/ Abcc6 expressions have been observed in many tissues, ${ }^{3,11,28}$ the bulk of the expression is found in the liver and kidneys. ${ }^{12,41}$ The transcriptional regulation of $A B C C 6 / A b c c 6$ has been studied, ${ }^{27,42}$ and we have shown that liver-specific modulators in combination with a synergistic effect between DNA methylation and Sp1 determine the mouse Abcc6 expression. ${ }^{12,23}$ In the present study, we found that $H \mathrm{Hb}^{\text {th } 3 /+}$ mice showed a progressive decrease in $A b c c 6$ expression associated with a reduction of Abcc6 protein levels. Because this decrease was liver specific, it was probably caused by the transcriptional elements involved in tissue specificity. Using protein/DNA arrays, liver nuclear extracts, and $2.9 \mathrm{~kb}$ of the Abcc6 promoter region, we identified 24 putative TFs that could potentially play a role in the down-regulation of Abcc6 in $\mathrm{Hb}^{\text {th } 3 /+}$ mice. Interestingly, 4 of these TFs (AP-2, USF-1, EGR, and NF-E2) were also found to bind the human $A B C C 6$ promoter ${ }^{27}$ which suggested that the regulation of the mouse $A b c c 6$ gene differs little from that of the human $A B C C 6$ gene. Of note, both NF-E2 and HNF- $4 \alpha$, which are essential modulators of the hepatic expression of $A b c c 6$, were detected by the protein/DNA array. In contrast, Sp1 was not detected despite the fact that it is required for the $A b c c 6 / A B C C 6$ expression in humans and mice. ${ }^{12,23,27}$ This discrepancy probably resulted from cross-hybridization between families of TFs, which recognize similar consensus sequences. Indeed, the Sp1, EGR, p53, and WT1 transcription factors are known to bind similar GC-rich DNA sequences. ${ }^{43-45}$ The liver extracts from the $H b b^{\text {th } 3 /+}$ and WT mice gave different patterns on the protein/DNA arrays (Supplemental Figure S1, see http://ajp.amjpathol.org), confirming that the down-regulation of $A b c c 6$ gene expression in liver probably occurred at the transcriptional level. We notably found that NF-E2 was no longer interacting with the Abcc6 promoter of 10 -month-old $\mathrm{Hbb}^{\text {th } 3 /+}$ mice, an age at which the gene expression is significantly decreased. The absence of NF-E2 on the Abcc6 proximal promoter suggested that either a change in the overall promoter conformation prevented the binding of certain TFs or the NF-E2 heterodimer was unable to form despite apparently normal gene expression levels. Another possibility was that NF-E2 might be heavily recruited for extramedullary expression of hemoglobin and other genes as a compensatory mechanism. However, because NF-E2 is a key regulator of many genes involved in iron homeosta- sis, heme biosynthesis, and globin protein synthesis, ${ }^{12,23,27,30}$ which are largely altered in $\beta$-thalassemia, it is possible that the function of Abcc6 might be related to one of these functions.

To determine whether the tissue-specific down-regulation of Abcc6 in $\mathrm{Hbb}^{\text {th } 3 /+}$ mice was also gene-specific, we examined the level of expression of other ATP-binding cassette transporter genes of the same family (Abcc1, $A b c c 2, A b c c 3$, and Abcc5). Of those four genes, only Abcc2 showed a slight, yet statistically significant, downregulation. Similarities between the promoters of Abcc6 and $A b c c 2$, notably the presence of several putative NFE2-binding sites, may be the reason for this decrease. Therefore, it is possible that $A b c c 2$ also responded to the same NF-E2-related molecular signal(s) as Abcc6. The down-regulation is also worth noting because of the results recently published by Hendig and colleagues, ${ }^{46}$ which showed changes in ATP-binding cassette transporter gene expression in response to ABCC6 knockdown (siRNA) or knockout (PXE fibroblasts). In this report, the human $A B C C 2$ is up-regulated in response to ABCC6 down-regulation or absence. Although apparently contradictory to our results and those of $\mathrm{Li}$ and colleagues, ${ }^{47}$ the context of Hendig's work was quite different and precludes a direct comparison of the results. Our data were obtained from liver tissues while their investigation was performed with cultured skin fibroblasts. However, both studies indicate that there might be common attributes in the regulation and/or functions of ABCC2/Abcc2 and ABCC6/Abcc6.

Because the human and mouse $A B C C 6 / A b c c 6$ genes share comparable transcriptional regulators, ${ }^{23,27,42}$ it is reasonable to propose that a down-regulation of ABCC6 expression, similar to the decrease we described in $H b b^{\text {th } 3 / 4}$ mice, also occurs in human patients with $\beta$-thalassemia. This may ultimately lead to the progressive development of PXE manifestations in some of these patients.

One could argue to the contrary because the $H b b^{\text {th } 3 / 4}$ mice did not develop an ectopic calcification phenotype in the time frame of our study. However, there are two major arguments supporting our claims: i) the Abcc6 protein decrease occurred progressively and became only significantly lower than the WT expression in old mice, and ii) the C57BL/6J background in which the $H b b^{\text {th3/+ }}$ deletion resides is not as conductive to mineralization as other congenic strains, such as $\mathrm{C} 3 \mathrm{H} / \mathrm{HeJ}, \mathrm{DBA} /$ $2 \mathrm{~J}$, or $129 \mathrm{~S} 1 / \mathrm{SVJ}{ }^{48,49}$ The latter strains develop severe dystrophic calcification after cardiovascular cryoinjuries, ischemia, or diet stimuli, ${ }^{50}$ which is a phenotype referred to as DCC. By examining F2 intercrosses of resistant mice C57BL/6J and susceptible animals $\mathrm{C} 3 \mathrm{H} / \mathrm{HeJ}$, Ivandic and colleagues ${ }^{51}$ identified a major susceptibility locus (Dyscalc1) on chromosome 7 and additional minor Dyscalc loci (Dyscalc2 to 4) on chromosomes 4, 12, and 14. Within the Dyscalc1 locus, a single Abcc6 mutation caused a $65 \%$ constitutive decrease in Abcc6 protein levels in liver and is directly responsible for the DCC phenotype. ${ }^{48,52}$ These three modifier loci that affect the penetrance and expression of the DCC phenotype ${ }^{50}$ and the Abcc6 DCC gene variant are all absent in the com- 
mon C57BL/6J strain, thereby explaining the relative "resistance" of the C57BL/6J to dystrophic mineralization. Interestingly, the DCC mice develop discrete mineralization in several tissues (unpublished data from L.M. and personal communication from Drs. O. Vanakker and Z. Aherrahrou), and these results clearly indicate that a combination between a specific genetic background and lower $A b c c 6$ expression lead to increased susceptibility to calcification.

The $\mathrm{Hbb}^{\text {th } 3 /+}$ mice used in the present study were not subjected to cardiac cryoinjuries, but this would certainly be a valuable experiment to confirm the role played by this ATP-binding cassette transporter and genetic background in the modulation of soft tissue mineralization. Also, the $\mathrm{Hbb}^{\text {th } 3 /+}$ mice could be crossed into the $\mathrm{C} 3 \mathrm{H} /$ HeJ background to verify if combining both the DCC and thalassemia genotypes would lead to a further increase in susceptibility to connective tissue mineralization similar to PXE. From the DCC mice results ${ }^{48,49}$ and the present study, it is clear that the level of ABCC6/Abcc6 transport activity in the liver is an influential modulator of calcification that expresses its potential in defined genetic contexts, not only with respect to PXE but also in regard to other pathologies involving ectopic mineralization. It is perhaps for these reasons that PXE manifestations have been reported with high prevalence in $\beta$-thalassemia patients of Greek and Italian descent.

In summary, our study showed a significant, progressive and liver-specific decrease of Abcc6 production in $H b b^{\text {th } 3 /+}$ mice. This down-regulation appeared to be mediated by changes in the transcriptional regulation of Abcc6. Despite the lack of obvious connective tissue mineralization in these mice, our study nevertheless suggested that the human $\beta$-thalassemia phenotype could induce similar molecular changes leading to a suboptimal ABCC6 endowment and increased susceptibility to dystrophic mineralization in dermal, ocular, and vascular tissue.

\section{Acknowledgments}

We thank Drs. Lut van Laer, Olivier Vanakker, and Anne De Paepe (University of Ghent, Belgium) and Christopher Brampton (University of Hawaii) for critical discussion and comments on the manuscript. We are also grateful to Miyoko Bellinger of the Histology and Imaging Core Facility at the John A. Burns School of Medicine, University of Hawaii.

\section{References}

1. Thein SL: Beta-thalassaemia. Baillieres Clin Haematol 1998, 11:91126

2. Aessopos A, Farmakis D, Loukopoulos D: Elastic tissue abnormalities resembling pseudoxanthoma elasticum in beta thalassemia and the sickling syndromes. Blood 2002, 99:30-35

3. Bergen AA, Plomp AS, Schuurman EJ, Terry S, Breuning M, Dauwerse H, Swart J, Kool M, van Soest S, Baas F, ten Brink JB, de Jong PT: Mutations in ABCC6 cause pseudoxanthoma elasticum. Nat Genet 2000, 25:228-231

4. Le Saux O, Urban Z, Tschuch C, Csiszar K, Bacchelli B, Quaglino D, Pasquali-Ronchetti I, Pope FM, Richards A, Terry S, Bercovitch L, de
Paepe A, Boyd CD: Mutations in a gene encoding an ABC transporter cause pseudoxanthoma elasticum. Nat Genet 2000, 25:223-227

5. Ringpfeil F, Lebwohl MG, Christiano AM, Uitto J: Pseudoxanthoma elasticum: mutations in the MRP6 gene encoding a transmembrane ATP-binding cassette (ABC) transporter. Proc Natl Acad Sci USA 2000, 97:6001-6006

6. Chassaing N, Martin L, Calvas P, Le Bert M, Hovnanian A: Pseudoxanthoma elasticum: a clinical, pathophysiological and genetic update including 11 novel ABCC6 mutations. J Med Genet 2005, 42: 881-892

7. Weenink AC, Dijkman G, de Meijer PH: Pseudoxanthoma elasticum and its complications: two case reports. Neth J Med 1996, 49:24-29

8. Neldner KH: Pseudoxanthoma elasticum. Int J Dermatol 1988, 27:98100

9. Li Q, Jiang Q, Pfendner E, Varadi A, Uitto J: Pseudoxanthoma elasticum: clinical phenotypes, molecular genetics and putative pathomechanisms. Exp Dermatol 2009, 18:1-11

10. Beck K, Hayashi K, Dang K, Hayashi M, Boyd CD: Analysis of ABCC6 (MRP6) in normal human tissues. Histochem Cell Biol 2005, 123:517528

11. Beck K, Hayashi K, Nishiguchi B, Le Saux O, Hayashi M, Boyd CD: The distribution of Abcc6 in normal mouse tissues suggests multiple functions for this ABC transporter. J Histochem Cytochem 2003, 51:887-902

12. Douet V, Heller MB, Le Saux O: DNA methylation and Sp1 binding determine the tissue-specific transcriptional activity of the mouse Abcc6 promoter. Biochem Biophys Res Commun 2007, 354:66-71

13. Le Saux O, Bunda S, Vanwart CM, Douet V, Got L, Martin L, Hinek A: Serum factors from pseudoxanthoma elasticum patients alter elastic fiber formation in vitro. J Invest Dermatol 2006, 126:1497-1505

14. Jiang Q, Endo M, Dibra F, Wang K, Uitto J: Pseudoxanthoma elasticum is a metabolic disease. J Invest Dermatol 2009, 129:348-354

15. Jiang Q, Oldenburg R, Otsuru S, Grand-Pierre AE, Horwitz EM, Uitto $\mathrm{J}$ : Parabiotic heterogenetic pairing of Abcc6-/-/Rag1-/- mice and their wild-type counterparts halts ectopic mineralization in a murine model of pseudoxanthoma elasticum. Am J Pathol 2010, 176:18551862

16. Hamlin N, Beck K, Bacchelli B, Cianciulli P, Pasquali-Ronchetti I, Le Saux O: Acquired pseudoxanthoma elasticum-like syndrome in betathalassaemia patients. Br J Haematol 2003, 122:852-854

17. Baccarani-Contri M, Bacchelli B, Boraldi F, Quaglino D, Taparelli F, Carnevali E, Francomano MA, Seidenari S, Bettoli V, De Sanctis V, Pasquali-Ronchetti I: Characterization of pseudoxanthoma elasticumlike lesions in the skin of patients with beta-thalassemia. J Am Acad Dermatol 2001, 44:33-39

18. Cianciulli P, Sorrentino F, Maffei L, Amadori S, Cappabianca MP, Foglietta E, Carnevali E, Pasquali-Ronchetti I: Cardiovascular involvement in thalassaemic patients with pseudoxanthoma elasticum-like skin lesions: a long-term follow-up study. Eur J Clin Invest 2002, 32:700-706

19. Farmakis D, Moyssakis I, Perakis A, Rombos Y, Deftereos S, Giakoumis A, Polymeropoulos E, Aessopos A: Unstable angina associated with coronary arterial calcification in a thalassemia intermedia patient with a pseudoxanthoma elasticum-like syndrome. Eur J Haematol 2003, 70:64-66

20. Farmakis D, Vesleme V, Papadogianni A, Tsaftaridis P, Kapralos P, Aessopos A: Aneurysmatic dilatation of ascending aorta in a patient with beta-thalassemia and a pseudoxanthoma elasticum-like syndrome. Ann Hematol 2004, 83:596-599

21. Yang B, Kirby S, Lewis J, Detloff PJ, Maeda N, Smithies O: A mouse model for beta 0-thalassemia. Proc Natl Acad Sci USA 1995, 92: 11608-11612

22. Prpic V, Green KC, Blackmore PF, Exton JH: Vasopressin-, angiotensin II-, and alpha 1-adrenergic-induced inhibition of $\mathrm{Ca}^{2+}$ transport by rat liver plasma membrane vesicles. J Biol Chem 1984, 259:13821385

23. Douet V, VanWart CM, Heller MB, Reinhard S, Le Saux O: HNF4alpha and NF-E2 are key transcriptional regulators of the murine Abcc6 gene expression. Biochim Biophys Acta 2006, 1759:426-436

24. Chakrabarti SK, James JC, Mirmira RG: Quantitative assessment of gene targeting in vitro and in vivo by the pancreatic transcription factor. Pdx1 Importance of chromatin structure in directing promoter binding. J Biol Chem 2002, 277:13286-13293 
25. Stockel B, Konig J, Nies AT, Cui Y, Brom M, Keppler D: Characterization of the $5^{\prime}$-flanking region of the human multidrug resistance protein 2 (MRP2) gene and its regulation in comparison with the multidrug resistance protein 3 (MRP3) gene. Eur J Biochem 2000, 267:1347-1358

26. Vollrath V, Wielandt AM, Iruretagoyena M, Chianale J: Role of Nrf2 in the regulation of the Mrp2 (ABCC2) gene. Biochem J 2006, 395:599609

27. Jiang Q, Matsuzaki Y, Li K, Uitto J: Transcriptional regulation and characterization of the promoter region of the human ABCC6 gene J Invest Dermatol 2006, 126:325-335

28. Matsuzaki Y, Nakano A, Jiang QJ, Pulkkinen L, Uitto J: Tissue-specific expression of the ABCC6 gene. J Invest Dermatol 2005, 125:900-905

29. Andrianaivo F, Lecocq M, Wattiaux-De Coninck S, Wattiaux R, Jadot M: Hydrodynamics-based transfection of the liver: entrance into hepatocytes of DNA that causes expression takes place very early after injection. J Gene Med 2004, 6:877-883

30. Andrews NC: The NF-E2 transcription factor. Int J Biochem Cell Bio 1998, 30:429-432

31. Gorgels TG, Hu X, Scheffer GL, van der Wal AC, Toonstra J, de Jong PT, van Kuppevelt TH, Levelt CN, de Wolf A, Loves WJ, Scheper RJ, Peek R, Bergen AA: Disruption of Abcc6 in the mouse: novel insight in the pathogenesis of pseudoxanthoma elasticum. Hum Mol Genet 2005, 14:1763-1773

32. Klement JF, Matsuzaki Y, Jiang QJ, Terlizzi J, Choi HY, Fujimoto N, Li K, Pulkkinen L, Birk DE, Sundberg JP, Uitto J: Targeted ablation of the abcc6 gene results in ectopic mineralization of connective tissues. Mol Cell Biol 2005, 25:8299-8310

33. Aessopos A, Samarkos M, Voskaridou E, Papaioannou D, Tsironi M, Kavouklis E, Vaiopoulos G, Stamatelos G, Loukopoulos D: Arterial calcifications in beta-thalassemia. Angiology 1998, 49:137-143

34. Aessopos A, Savvides P, Stamatelos G, Rombos I, Tassiopoulos T, Karagiorga M, Kaklamanis $P$, Fessas P: Pseudoxanthoma elasticumlike skin lesions and angioid streaks in beta- thalassemia. Am J Hematol 1992, 41:159-164

35. Hershko C, Konijn AM, Link G: Iron chelators for thalassaemia. Br J Haematol 1998, 101:399-406

36. Rinaldi M, Della Corte M, Ruocco V, D'Onofrio C, Zanotta G, Romano A: Ocular involvement correlated with age in patients affected by major and intermedia beta-thalassemia treated or not with desferrioxamine. Metab Pediatr Syst Ophthalmol 1993, 16:23-25

37. Samarkos M, Aessopos A, Fragodimitri C, Karagiorga M, Kalotychou V, Voskaridou E, Kavouklis E, Loukopoulos D: Neutrophil elastase in patients with homozygous beta-thalassemia and pseudoxanthoma elasticum-like syndrome. Am J Hematol 2000, 63:63-67

38. Tsomi K, Karagiorga-Lagana M, Fragodimitri C, Karabatsos F, Katsiki V: Arterial elastorrhexis: manifestation of a generalized elastic tissue disorder in beta-thalassaemia major. Eur J Haematol 1999, 63:287294
39. Gartaganis S, Ismiridis K, Papageorgiou O, Beratis NG, Papanastasiou D: Ocular abnormalities in patients with beta thalassemia. Am J Ophthalmol 1989, 108:699-703

40. Bunda S, Kaviani N, Hinek A: Fluctuations of intracellular iron modulate elastin production. J Biol Chem 2005, 280:2341-2351

41. Kool M, van der Linden M, de Haas M, Baas F, Borst P: Expression of human MRP6, a homologue of the multidrug resistance protein gene MRP1, in tissues and cancer cells. Cancer Res 1999, 59:175-182

42. Aranyi T, Ratajewski M, Bardoczy V, Pulaski L, Bors A, Tordai A Varadi $A$ : Identification of a DNA methylation-dependent activator sequence in the pseudoxanthoma elasticum gene. ABCC6, J Biol Chem 2005, 280:18643-18650

43. Khachigian LM, Williams AJ, Collins T: Interplay of Sp1 and Egr-1 in the proximal platelet-derived growth factor A-chain promoter in cultured vascular endothelial cells. J Biol Chem 1995, 270:27679-27686

44. Nakagama H, Heinrich G, Pelletier J, Housman DE: Sequence and structural requirements for high-affinity DNA binding by the WT1 gene product. Mol Cell Biol 1995, 15:1489-1498

45. Rauscher FJ, 3rd, Morris JF, Tournay OE, Cook DM, Curran T: Binding of the Wilms' tumor locus zinc finger protein to the EGR-1 consensus sequence. Science 1990, 250:1259-1262

46. Hendig D, Langmann T, Kocken S, Zarbock R, Szliska C, Schmitz G, Kleesiek K, Gotting C: Gene expression profiling of ABC transporters in dermal fibroblasts of pseudoxanthoma elasticum patients identifies new candidates involved in PXE pathogenesis. Lab Invest 2008, 88:1303-1315

47. Li Q, Jiang Q, Larusso J, Klement JF, Sartorelli AC, Belinsky MG, Kruh GD, Uitto J: Targeted ablation of Abcc1 or Abcc3 in Abcc6(-/-) mice does not modify the ectopic mineralization process. Exp Dermatol 2007, 16:853-859

48. Aherrahrou Z, Doehring LC, Ehlers EM, Liptau H, Depping R, LinselNitschke P, Kaczmarek PM, Erdmann J, Schunkert H: An alternative splice variant in Abcc6, the gene causing dystrophic calcification, leads to protein deficiency in $\mathrm{C} 3 \mathrm{H} / \mathrm{He}$ mice. J Biol Chem 2008, 283:7608-7615

49. Sheng MH, Lau KH, Beamer WG, Baylink DJ, Wergedal JE: In vivo and in vitro evidence that the high osteoblastic activity in $\mathrm{C} 3 \mathrm{H} / \mathrm{HeJ}$ mice compared to $\mathrm{C} 57 \mathrm{BL} / 6 \mathrm{~J}$ mice is intrinsic to bone cells. Bone 2004, 35:711-719

50. Ivandic BT, Utz HF, Kaczmarek PM, Aherrahrou Z, Axtner SB, Klepsch C, Lusis AJ, Katus HA: New Dyscalc loci for myocardial cell necrosis and calcification (dystrophic cardiac calcinosis) in mice. Physiol Genomics 2001, 6:137-144

51. Ivandic BT, Qiao JH, Machleder D, Liao F, Drake TA, Lusis AJ: A locus on chromosome 7 determines myocardial cell necrosis and calcification (dystrophic cardiac calcinosis) in mice. Proc Natl Acad Sci USA 1996, 93:5483-5488

52. Meng H, Vera I, Che N, Wang X, Wang SS, Ingram-Drake L, Schadt EE, Drake TA, Lusis AJ: Identification of Abcc6 as the major causal gene for dystrophic cardiac calcification in mice through integrative genomics. Proc Natl Acad Sci USA 2007, 104:4530-4535 